\title{
WASTE HEAT GENERATION AND POTENTIAL RECOVERY SYSTEMS USED IN SRI LANKAN HOTELS
}

\author{
N. Lakshan ${ }^{1}$, T. Ramachandra ${ }^{2}$ and U.G.D. Madushika ${ }^{3}$
}

\begin{abstract}
The waste heat recovery concept can be used as a solution to optimise energy consumption while reducing the waste heat in energy generation systems. However, its application in Sri Lankan hotels is still in the infancy stage even though the hotel sector accounts for high energy consumption. Therefore, this research aimed to assess the amount of waste heat generated from the different sources in hotel buildings and thereby identify the most appropriate waste heat recovery systems to the hotel buildings in Sri Lanka through a comparative case study analysis of three similar natured hotel buildings. The required data to perform waste heat calculation were extracted through document reviews and site visits. This study identified the three main waste heat generating sources in hotel buildings: HVAC condenser out, boiler exhaust, and kitchen exhaust. The analysis shows that the condenser out of the HVAC system is the highest waste heat generating source which accounts for an average of 41,823GJ per year while boiler exhaust and kitchen exhaust generate the waste heat of an average of 11,000GJ and $8 G J$ per year. It is further found that the quality of waste heat generated from the boiler exhaust is higher than the condenser out of the HVAC system and kitchen exhaust. Hence, this study concludes that the boiler has the highest potential of using the waste heat recovery system than the condenser out of the HVAC.
\end{abstract}

Keywords: Hotel building; Waste heat source; Waste heat; Waste heat recovery system.

\section{INTRODUCTION}

Currently, the world population is about 7.5 billion, and by the year 2050, it is expected to reach 9.9 billion (Population Reference Bureau [PRB], 2019). With the increment of population, people tend to increase the industrial activities to fulfil human requirements. According to the U.S. Energy Information Administration (2017), industrial sector accounts for $35 \%$ of global energy consumption. However, $20-50 \%$ of heat is ultimately discharged to the environment as waste heat from the energy consumption in the industrial sector (Papapetrou et al., 2018). According to environmentalists, unsustainable Green House Gases (GHG) and tons of toxic gases are released into the atmosphere because of this heat discharging. Most of the recent researchers identified this as the major reason for global warming and climatic changes (Gunggut et al., 2014). These burning

\footnotetext{
${ }^{1}$ Department of Building Economics, University of Moratuwa, Sri Lanka, nalindalakshan111@gmail.com

${ }^{2}$ Department of Building Economics, University of Moratuwa, Sri Lanka, thanujar@uom.lk

${ }^{3}$ Department of Building Economics, University of Moratuwa, Sri Lanka,

dilakshimadushika96@gmail.com
} 
environmental limitations motivate to reduce energy consumption and utilise the waste heat in the industrial sector (Forman et al., 2016).

Currently, there are various technologies used to minimise energy waste and thereby improve the efficiency of energy conversion. However, a considerable percentage of energy is still wasted in the forms of solids, gas, or liquid while a large part of the waste energy can be recovered (Irwindale, 2008). Waste heat recovery is a better application that has been used in the industry to optimise energy consumption while reducing the environmental impact that occurred in energy generation systems in the global context (Liu et al., 2004). According to Teke et al. (2009), a heat recovery system can contribute to the reduction in $\mathrm{CO}_{2}$ emissions to the environment.

In Sri Lanka, the industrial sector accounts for 39\% of annual energy consumption and generates about $48 \%$ of $\mathrm{CO}_{2}$ to the atmosphere (Ministry of Power and Energy, 2016). It is found that the most energy-consuming industries in Sri Lanka are tea, apparel, hotel, commercial, food and beverage, tire, steel and iron, pulp, and paper sectors (Sri Lanka Sustainable Energy Authority, 2017). These industries together contribute about $25 \%$ of the annual Gross Domestic Product (GDP) of Sri Lanka (Central Bank of Sri Lanka, 2019).

Among those industries, the hotel sector is consuming around 5\% of grid electricity and other liquid and solid fuels including furnace oil, diesel, biomass (Sri Lanka Sustainable Energy Authority, 2017). In most hotel buildings, electricity is the popular energy source that is used to operate HVAC, mechanical transport, lighting, and all other systems in the building. Cooking activities are facilitated by liquid petroleum. Apart from that biomass, diesel, or furnace oil are used in boiler operation as an energy source for boilers (Perera et al., 2005). Therefore, hotel sectors could be considered as the major contributors to the increment of energy consumption and negative environmental impacts in the country. However, the hotel sector currently accounts for about $12 \%$ of Sri Lankan GDP (Central Bank of Sri Lanka, 2019). Hence, this indicates that improving energy efficiency through waste heat recovery systems could help to improve the economy and to reduce $\mathrm{CO}_{2}$ emissions. Even though the waste heat recovery system can minimise the primary energy source usage and emission of $\mathrm{CO}_{2}$ to the environment, the waste heat recovery concept is still at a lower level in the Sri Lankan context. Hence, this study aimed to assess the amount of waste heat generated from the different sources in hotel buildings and thereby identify the most appropriate waste heat recovery systems used in the hotel buildings in Sri Lanka.

\section{LITERATURE REVIEW}

\subsection{DEFINITION OF WASTE HEAT}

Waste heat is the heat that is released into the environment by combustion or chemical reactions, that can be reused for useful and economic purposes (Karellas et al., 2013). Waste heat is emitted and released in a variety of ways, including radiation, cooling fluid, exhaust gas, and air, wherever products are produced, and machines are run (Bruckner et al., 2015). The authors further depicted that approximately $30 \%$ of the input energy is lost due to waste heat in the industrial sector. Waste heat can be categorised into three temperature stages; High temperature (heat at temperatures greater than $400{ }^{\circ} \mathrm{C}$ ), Medium temperature (heat at temperatures $100^{\circ} \mathrm{C}-400^{\circ} \mathrm{C}$ ), Low temperature (heat at temperatures less than $100^{\circ} \mathrm{C}$ ) (Bruckner et al., 2015). According to above authors, direct combustion 
is the source to generate waste heat in the high-temperature range, while the exhaust of combustion units and the process unit components products and the equipment generate medium range and low-temperature range heat respectively.

\subsection{WASTE HEAT RECOVERY SYSTEMS}

A waste heat recovery system is a kind of technology used for the effective adoption of waste heat generated from different sources (Jouhara et al., 2018). Those technologies can be passive or active. In active waste heat recovery systems, waste heat is directly used at the same or low or high temperature or transformed the waste heat into another form of energy. Heat exchangers and thermal energy storages are the main passive waste heat recovery systems (Bruckner et al., 2015). Figure 1 further illustrates the different types of passive and active waste heat recovery systems.

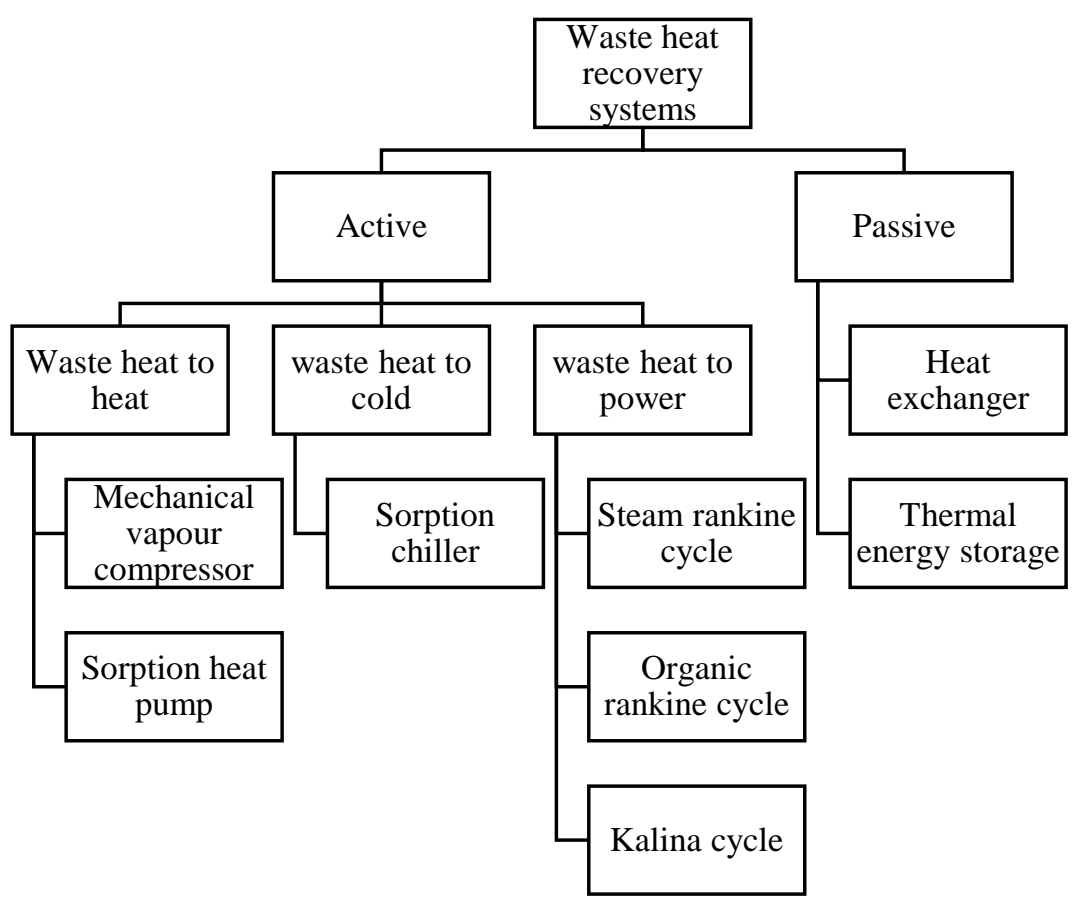

Figure 1: Waste heat recovery systems (Source: Bruckner et al., 2015)

Recently, the energy demand for heating and cooling has been reduced as a result of the usage of the heat recovery system due to its ability to limit heat losses and optimised energy consumption (Pfafferott, 2003). However, the application of a waste heat recovery system depends on the temperature range of generated waste heat (Tafone et al., 2017). There are three important factors to consider in selecting a waste heat recovery system; quantity, quality, and temporal availability (Arzbaecher et al., 2007). According to the authors, quantity, quality, and temporal availability refers to amount of waste heat generation, temperature of the generated waste heat and the availability of the waste heat when it is required, respectively. The quality of the waste heat depends on the waste heat source (Tafone et al., 2017). Table 1 illustrates the quality of waste heat and its uses of different waste heat sources. 
Table 1: Waste heat source and quality

\begin{tabular}{cll}
\hline Source & \multicolumn{1}{c}{ Source of Waste Heat } & \multicolumn{1}{c}{ Quality of Waste Heat } \\
\hline 1 & Heat in flue gases & High Temperature \\
2 & Heat in vapor streams & High Temperature \\
3 & $\begin{array}{l}\text { Convective and radiant heat lost from the } \\
\text { exterior of equipment }\end{array}$ & Low Temperature \\
4 & Heat losses in cooling water & Low Temperature \\
5 & $\begin{array}{l}\text { Heat losses in providing chilled water or in the } \\
\text { disposal of chilled water }\end{array}$ & $\begin{array}{l}\text { High or Low Temperature (Based } \\
\text { on usage of refrigeration) } \\
6\end{array}$ \\
$\begin{array}{l}\text { Heat stored in products leaving the process } \\
\text { Heat in gaseous \& liquid effluents leaving }\end{array}$ & $\begin{array}{l}\text { Medium Temperature } \\
\text { process }\end{array}$ \\
\hline
\end{tabular}

(Source: Jouhara et al., 2018)

Generally, waste heat in high temperatures accounts for the higher quality waste recovery as well as more cost-effectiveness. Similarly, waste heat in low temperatures accounts for low-quality waste recovery with minimum cost-saving (Tafone et al., 2017).

The total amount of waste generated from the different sources cannot be fully recovered (Arzbaecher et al., 2007). Hence, it is important to identify the most suitable heat recovery system which gives the maximum amount of heat recoverable and maximum efficiency. Furthermore, regenerative and recuperative burners, economizers, waste heat boilers, air preheaters, rotary regenerators, run-around coil, plate heat exchangers, heat pipe systems, and heat pumps are the most commonly available waste heat recovery systems (Tafone et al., 2017). Table 2 illustrates the applicability of waste heat recovery systems.

Table 2: Application of waste heat recovery technologies

\begin{tabular}{lcc}
\hline Waste Heat Recovery System & Quality of Waste Heat & $\begin{array}{c}\text { Relevant Waste Heat } \\
\text { Sources } \\
\text { (Reference to Table 1) }\end{array}$ \\
\hline Regenerative Burners & High & 1,2 \\
Recuperative Burners & High & 1,2 \\
Economisers & Low - Medium & $3,4,5,6,7$ \\
Waste Heat Boilers & Medium-High & $1,2,5,6$ \\
Recuperators & Low - High & 1,2 \\
Regenerators & Medium - High & $1,2,5,6$ \\
Rotary Regenerators & Low - Medium & $3,4,5,6,7$ \\
Run around coil (RAC) & Medium - High & $1,2,5,6$ \\
Heat Recovery Steam & High & 1,2 \\
Generator (HRSG) & & $1,2,5,6$ \\
Plate Heat Exchanger & Medium-High & $1,2,5,6$ \\
Heat Pipe Systems & Medium-High & $1,2,5,6$ \\
Thermoelectric Generation & Medium - High & $3,4,7$ \\
Piezoelectric Power & Low & \\
\hline
\end{tabular}




\begin{tabular}{lcc}
\hline Waste Heat Recovery System & Quality of Waste Heat & $\begin{array}{c}\text { Relevant Waste Heat } \\
\text { Sources } \\
\text { (Reference to Table 1) }\end{array}$ \\
\hline $\begin{array}{l}\text { Generation } \\
\begin{array}{l}\text { Thermionic Generator } \\
\text { Thermo Photo Voltaic (TPV) }\end{array}\end{array}$ & High & 1,2 \\
$\begin{array}{l}\text { Generator } \\
\text { Heat Pump }\end{array}$ & Low -Medium & $1,2,3,4,5,6,7$ \\
$\begin{array}{l}\text { Direct Contact Condensation } \\
\text { Recovery }\end{array}$ & Medium-High & $3,4,5,6,7$ \\
$\begin{array}{l}\text { Indirect Contact Condensation } \\
\text { Recovery } \\
\text { Transport Membrane }\end{array}$ & Medium-High & $1,2,5,6$ \\
Condenser & Medium-High & $1,2,5,6$ \\
\hline
\end{tabular}

(Source: Jouhara et al., 2018)

However, the literature findings proved that it is not appropriate suggesting a suitable waste heat recovery system to a source only based on calculating the generated waste heat amount. It is because of a considerable amount of heat is lost while recovering. Hence, before selecting a suitable waste heat recovery system it is important to focus on the waste heat recoverable amount in the sources.

Therefore, this research aimed to assess the amount of waste heat generated from different sources in hotel buildings and thereby identify the most appropriate waste heat recovery systems that can be used in the hotel buildings in Sri Lanka.

\section{RESEARCH METHODOLOGY}

The research was conducted using a quantitative data collection and comparative data analysis techniques. Initially, a preliminary investigation was carried out through site visits to identify the most suitable research cases for this study. Furthermore, for this comparative study, there needs to be similar natured hotel buildings to calculate the amount of waste heat generated from selected waste heat sources. When finding cases, it was important to focus on minimising errors that could occur due to the deviation of physical properties of those selected cases. Hence, when selecting the cases, due consideration was given to the factors affecting the waste heat generation, such as the rating of the hotel, occupancy, and waste heat generated sources and thereby to ensure the reliability and accuracy of the research findings.

Given the constraints of time and accessibility, three hotel buildings which fulfil the above requirements were identified during the preliminary investigation. Subsequently, interviews conducted with management of selected hotels identified that the HVAC condenser out, boiler exhaust, and kitchen exhaust as the most common waste heat sources in those hotels. Table 3 illustrates the profile of the three hotels studied. 
Table 3: Profile of three hotel buildings

\begin{tabular}{|c|c|c|c|c|c|c|}
\hline \multirow[t]{2}{*}{ Hotel } & \multirow{2}{*}{$\begin{array}{l}\text { No. of } \\
\text { rooms }\end{array}$} & \multirow{2}{*}{$\begin{array}{l}\text { No. } \\
\text { floors }\end{array}$} & \multirow{2}{*}{$\begin{array}{c}\text { No. of } \\
\text { occupied } \\
\text { rooms (Avg.) }\end{array}$} & \multicolumn{3}{|c|}{ System description } \\
\hline & & & & System & Type & Capacit. \\
\hline \multirow[t]{3}{*}{01} & 500 & 14 & 281 & Chiller & Water cooled centrifugal type & 1050TR \\
\hline & & & & Boiler & Three pass fire tube & $6 \mathrm{~T} / \mathrm{H}$ \\
\hline & & & & $\begin{array}{l}\text { Kitchen } \\
\text { exhaust }\end{array}$ & $\begin{array}{l}\text { Back shelf type with } \\
\text { extraction fans }\end{array}$ & $691 / \mathrm{s}$ \\
\hline \multirow[t]{3}{*}{$\mathbf{0 2}$} & 501 & 18 & 257 & Chiller & Water cooled centrifugal type & 1050TR \\
\hline & & & & Boiler & Three pass fire tube & $7.3 \mathrm{~T} / \mathrm{H}$ \\
\hline & & & & $\begin{array}{l}\text { Kitchen } \\
\text { exhaust }\end{array}$ & $\begin{array}{l}\text { Back shelf type with } \\
\text { extraction fans }\end{array}$ & $601 / \mathrm{s}$ \\
\hline \multirow[t]{3}{*}{$\mathbf{0 3}$} & 450 & 19 & 236 & Chiller & Water cooled screw type & 1000TR \\
\hline & & & & Boiler & Back flame fire tube & $7.2 \mathrm{~T} / \mathrm{H}$ \\
\hline & & & & $\begin{array}{l}\text { Kitchen } \\
\text { exhaust }\end{array}$ & $\begin{array}{l}\text { Back shelf type with } \\
\text { extraction fans }\end{array}$ & $87 \mathrm{~s} / 1$ \\
\hline
\end{tabular}

Furthermore, the data required to calculate the waste heat amount was collected through expert interviews and documentary reviews of relevant standards which describe the operation of selected systems. The following equation 01 was used to calculate the generated waste heat quantity from each source in the selected three buildings.

$$
Q=V \times \rho \times C P \times \Delta T
$$

Where, $\mathrm{Q}(\mathrm{J})$ is the heat content, $\mathrm{V}$ is the flow rate $\left(\mathrm{m}^{3} / \mathrm{s}\right), \rho$ is the density of the flue gas $\left(\mathrm{kg} / \mathrm{m}^{3}\right), \mathrm{Cp}$ is the specific heat $(\mathrm{J} / \mathrm{kgK})$ and $\Delta \mathrm{T}$ is the temperature difference $(\mathrm{K})$.

Subsequently, three expert interviews were conducted with the hotel management of the selected hotels to identify the suitable waste heat recovery systems that can be used for the identified waste heat sources; boiler exhaust, condenser out of the HVAC system, and kitchen exhaust.

\section{DATA ANALYSIS AND FINDINGS}

Table 4 illustrates the calculated waste heat amounts of different sources in each building as per equation 1 . The temperature difference and flow rate of waste heat were collected through the site visits and interviews among the experts in that hotel buildings. Specific heat capacity and density were gathered by referring to standards.

Generated waste heat amounts from the HVAC condenser out in Hotel 01 can be elaborated as follows:

Where, $\mathrm{V}=89 \mathrm{~kg} / \mathrm{s}, \rho=997 \mathrm{~kg} / \mathrm{m}^{3}, \mathrm{Cp}=4200 \mathrm{~J} / \mathrm{kg}^{0} \mathrm{C}, \Delta \mathrm{T}=6^{0} \mathrm{C}$

$\underline{\mathrm{Q}=2,242,800 \mathrm{~J} / \mathrm{s}}$

However, this could vary depending on the working time of the selected source. The working time per day of identified sources was obtained by referring to the daily records available at each hotel. The mean value of operating hours within 30 days was taken as the operating time of each source. Accordingly, it was calculated as 24 hours, 20 hours, 
and 10 hours per day for the HVAC system, boiler exhaust, and kitchen exhaust, respectively.

Table 4: Generated waste heat amounts of different sources in each building

\begin{tabular}{lccccccc}
\hline \multicolumn{1}{c}{ System } & Hotel & Medium & \multicolumn{2}{c}{ Temperature $\left({ }^{\mathbf{0}} \mathbf{C}\right)$} & Flow rate & \multicolumn{2}{c}{ Waste heat amount } \\
& & & Range & Quality & $(\mathbf{k g} / \mathbf{s})$ & $(\mathbf{J} / \mathbf{s})$ & $(\mathbf{G J} / \mathbf{y})$ \\
\hline $\begin{array}{l}\text { HVAC } \\
\begin{array}{l}\text { condenser } \\
\text { out }\end{array}\end{array}$ & H1 & Water & $30-36$ & Low & 89.0 & 2242800 & 70729 \\
& H2 & Water & $30-35$ & Low & 63.15 & 1326215 & 41824 \\
& H3 & Water & $30-36$ & Low & 70.0 & 2058000 & 64901 \\
$\begin{array}{l}\text { Boiler } \\
\text { exhaust }\end{array}$ & H1 & Air & $30-180$ & Medium & 1.63 & 295719 & 8549 \\
& H2 & Air & $30-210$ & Medium & 2.34 & 508248 & 14692 \\
& H3 & Air & $30-190$ & Medium & 1.76 & 339066 & 9802 \\
$\begin{array}{l}\text { Kitchen } \\
\text { exhaust }\end{array}$ & H1 & Air & $30-35$ & Low & 0.06 & 364 & 5 \\
& H2 & Air & $30-38$ & Low & 0.05 & 437 & 6 \\
& H3 & Air & $30-40$ & Low & 0.09 & 1092 & 15 \\
\hline
\end{tabular}

As per Table 4, condenser out of HVAC system and kitchen exhaust belongs to the lowtemperature category in each building while boiler exhaust belongs to the medium temperature category. It is seen that the quality of waste heat generated from the boiler exhaust is higher than the quality of waste heat generated from the condenser out of the HVAC system and kitchen exhaust.

When considering the quantity of waste heat generated from the identified sources, the condenser out of the HVAC system is the highest waste heat generating source. It generates an average of 41,823 GJ per year. In the same vein, the boiler exhaust produces $11,000 \mathrm{GJ}$ of waste heat per year on average while the kitchen exhaust produces only an average of $8 \mathrm{GJ}$ per year. Hence, kitchen exhaust is the minimum waste heat generating source among the identified sources.

The result of this calculation shows that the quality and the quantity of generated waste heat of kitchen exhaust in hotel buildings are very less compared to the other two sources. However, literature findings evident that the sources which generate less waste heat amount and emit low temperature are not cost-effective in the waste heat recovery concept. Furthermore, even though the condenser out of the HVAC system shows a high quantity of waste heat, the quality of the waste heat is less and no more cost-effective. Hence, boiler exhaust could be considered as the best waste heat source for waste heat recovery among the identified sources.

Based on the assessment of waste heat generation, it is difficult to suggest the appropriate waste heat recovery systems for the identified waste heat sources in the hotel sector due to the technological constraints in Sri Lanka. Hence, following the assessment, experts were approached to recommend the most appropriate waste heat recovery systems that can be used for these waste heat sources. Table 5 illustrates the different waste heat 
recovery systems that can be used for the boiler exhaust and condenser out of the HVAC systems.

Table 5: Waste heat recovery systems for boiler exhaust and condenser out of the HVAC systems

\begin{tabular}{|c|c|}
\hline Boiler Exhaust & Condenser out of the HVAC systems \\
\hline $\begin{array}{l}\text { 1. Hot water generation with heat pump } \\
\text { method }\end{array}$ & $\begin{array}{l}\text { 1. Hot water generation with heat pump } \\
\text { method }\end{array}$ \\
\hline $\begin{array}{l}\text { 2. Hot water generation with direct heat } \\
\text { exchanger }\end{array}$ & $\begin{array}{l}\text { 2. Hot water generation with direct heat } \\
\text { exchanger }\end{array}$ \\
\hline $\begin{array}{l}\text { 3. Boiler combustion air-free heat with } \\
\text { direct heat exchanger }\end{array}$ & $\begin{array}{l}\text { 3. Hot water generation with vapor } \\
\text { compression refrigeration }\end{array}$ \\
\hline $\begin{array}{l}\text { 4. Furness oil-free heat with direct heat } \\
\text { exchanger }\end{array}$ & \\
\hline
\end{tabular}

As shown in Tables 5, there are four types of waste heat recovery systems used for the boiler exhaust; (1) hot water generation with heat pump method, (2) hot water generation with direct heat exchanger, (3) boiler combustion air-free heat with direct heat exchanger, and (4) furnace oil-free heat with direct heat exchanger. Amongst, the hot water generation with direct heat exchanger was recommended as the most suitable waste heat recovery system for the boiler exhaust in the hotel industry, mainly due to two reasons: (1) In the hotel industry, boilers are mainly used for the steam and hot water generation and (2) Heat exchangers are more efficient and effective than heat pumps.

An expert elaborated;

"Boiler exhaust is a main waste heat source in a hotel. The boiler exhaust temperature is nearly $250^{\circ} \mathrm{C}$, depending on boiler capacity and the operating time. If there is a close circuit boiler circulation, it can collect waste steam directly to the boiler feeding tank. Similarly, we can generate hot water by using exhaust heat through the heat exchanger (economizer). Because the normal water temperature is $30^{\circ} \mathrm{C}-35^{\circ} \mathrm{C}$ and the boiling point is $100^{\circ} \mathrm{C}$. Therefore, we should spend more energy to heat water $\left(65^{\circ} \mathrm{C}-70^{\circ} \mathrm{C}\right)$. Although, when using feed water through the economizer (heat exchanger) organisation can save more energy. Therefore, hot water generation with direct heat exchanger is the most effective waste heat recovery method for boiler exhaust".

This was further strengthened by an expert stating;

"Boiler exhaust directly emits more heat (around 3000C<) to the environment. When recovering the heat for hot water generation and may affect energy saving. When considering waste heat recovery systems, heat exchangers are more effective than heat pumps".

Another expert pointed;

"Relatively boiler exhaust emits more heat than other waste heat sources. In the hotel industry boilers are used for steam generation and hot water generation. As in cold country, we are recovering waste heat to heat swimming pool water. Therefore, a heat exchanger (like economizers) is effective to recover waste heat from exhaust".

Similarly, experts stated that there are three main types of waste heat recovery systems used for the condenser out of the HVAC systems: (1) hot water generation with heat pump method, (2) hot water generation with direct heat exchanger, and (3) hot water generation with vapor compression refrigeration. Amongst, hot water generation with a direct heat 
exchanger is the most suitable waste heat recovery system for the condenser out of the HVAC systems in the hotel industry.

An expert stated;

"Air-cooled chillers are the best type than water-cooled chillers for heat recovery. The watercooled type uses cooling towers to decrease chilled water temperature, but air-cooled type chillers use environmental temperature (air) to cool down. Therefore, this method is most suitable for air-cooled chillers. Through the heat exchangers, it can be recovered the waste heat from the HVAC system."

Another expert opined;

"Hot water generation with direct heat exchanger is most suitable than hot water generation with vapor compression refrigeration and using the heat pump to recover heat loss of chillers because replacing a heat exchanger is more effective than the heat pump."

Hence, experts evident that the hot water generation with a direct heat exchanger is the most suitable waste heat recovery system for both boiler exhaust and condenser out of the HVAC system.

\section{CONCLUSIONS}

Industrial waste heat refers to the heat lost to the environment through the different industrial processes. Waste heat recovery is the method used to reuse the lost heat through industrial processes. Waste heat recovery systems are introduced to the waste sources based on the waste heat ranges such as high temperature, low temperature, and medium temperature. Furthermore, quantity, quality, and temporal availability are the main factors to be considered in selecting the waste recovery system.

The findings of this study identified that the main three waste heat generated sources in Sri Lankan hotel buildings include HVAC condenser out, boiler exhaust, and kitchen exhaust. According to the calculations, the condenser out of the HVAC system is the highest waste heat generating source is at an average of $41,823 \mathrm{GJ}$ per year. Then respectively, boiler exhaust is at an average of 11,000GJ per year and kitchen exhaust is at an average of 8GJ per year. Furthermore, analysis shows the quality of waste heat generated from the boiler exhaust is higher than the quality of waste heat generated from the condenser out of the HVAC system and kitchen exhaust. Subsequently, it concluded that the usage of a waste heat recovery system for the kitchen exhaust waste source in the Sri Lankan hotel sector will be less effective. This study further identified that hot water generation with a direct heat exchanger is the most suitable waste heat recovery system for both boiler exhaust and condenser out of the HVAC system among the available different waste heat recovery systems.

This study is limited to the HVAC condenser out, boiler exhaust, and kitchen exhaust waste sources in the Sri Lankan hotel sector. However, many other industries generate waste heat from their day-to-day operations. Therefore, it is suggested the future studies to assess the waste heat generated from different industrial processes to introduce waste heat recovery systems and thereby reduce the non-renewable energy consumption in the country. 


\section{ACKNOWLEDGEMENT}

Authors greatly acknowledge the financial support provided by the Senate Research Committee of University of Moratuwa under the Grants SRC/ST/2020/04.

\section{REFERENCES}

Arzbaecher, C., Fouche, E. and Parmenter, K., 2007. Industrial waste-heat recovery: benefits and recent advancements in technology and applications, ACEEE Summer Study on Energy Efficiency in Industry, pp. 1-13.

Brückner, S., Liu, S., Miró, L., Radspieler, M., Cabeza, L.F. and Lävemann, E., 2015. Industrial waste heat recovery technologies: An economic analysis of heat transformation technologies. Applied Energy, 151, pp.157-167.

Central Bank of Sri Lanka, 2019. Annual report 2019, Colombo: Central Bank of Sri Lanka.

Forman, C., Muritala, I.K., Pardemann, R. and Meyer, B., 2016. Estimating the global waste heat potential. Renewable and Sustainable Energy Reviews, pp. 1568-1579.

Gunggut, H., Saufi, D.S.N.S.A.M., Zaaba, Z. and Liu, M.S.M., 2014 . Where have all the forests gone? Deforestation in land below the wind. Social and Behavioral Sciences, 153, p. 363-369.

Irwindale, 2008. Cooling, heating, generating power, and recovering waste heat with thermoelectric systems. Science, 321(5895), pp. 1457-1461.

Jouhara, H. et al., 2018. Waste heat recovery technologies and applications. Thermal Science and Engineering Progress, 6, pp. 268-289.

Karellas, S. et al., 2013. Energetic and exergetic analysis of waste heat recovery systems in the cement industry. Energy, pp. 1-10.

Liu, B. T., Chien, K.H. and Wang, C.C., 2004. Effect of working fluids on organic rankine cycle for waste heat recovery. Energy, pp. 1207-1217.

Ministry of power and energy, 2016. Sri Lanka energy sector development plan for a knowledge based economy, Sri Lanka: Ministry of power and energy.

Papapetrou, M., Kosmadakis, G., Cipollina, A., La Commare, U. and Micale, G., 2018. Industrial waste heat: estimation of the technically available resource in the EU per industrial sector, temperature level and country. Applied Thermal Engineering, 138, pp. 207-216.

Perera, K.K.C.K., Rathnasiri, P.G., Senarath, S.A.S., Sugathapala, A.G.T., Bhattacharya, S.C. and Salam, P.A., 2005. Assessment of sustainable energy potential of non-plantation biomass resources in Sri Lanka. Biomass and Bioenergy, 29(3), pp.199-213..

Pfafferott, 2003. Evaluation of earth-to-air heat exchangers with a standardised method to calculate energy efficiency. Energy and Buildings, pp. 971-983.

Population Reference Bureau [PRB], 2019. 2019 World population data sheet. Colombo: Population Reference Bureau.

Sri Lanka Sustainable Energy Authority, 2017. Improvement of energy utilization efficiency in hotel sector. Colombo: Sri Lanka Sustainable Energy Authority. [Online] Available from: http://www.powermin.gov.lk: http://www.energy.gov.lk/your-business/sector-specific-programs/hotelindustry

Tafone, A., Borri, E., Comodi, G., van den Broek, M. and Romagnoli, A., 2017. Preliminary assessment of waste heat recovery solution (ORC) to enhance the performance of liquid air energy storage system. Energy Proceedia, 142, pp. 3609-3616.

Teke, I., Agra, O., Atayılmaz, S.O. and Demir, H., 2009. Determining the best type of heat exchangers for heat recovery. Applied Thermal Engineering, pp. 577-583.

U.S. Energy Information Administration, 2017. International Energy Outlook 2017.U.S. Washington: U.S. Energy Information Administration 